\title{
انتقاهية العدد
}

يطيب لأسرة كلية الدراسات الاقتصادية والعلوم السياسية بجامعة الإسكندرية أن تقدم للباحثين والقراء العرب العدد السابع من مجلتها العلمية (يناير 2019). ويضم العدد خمس دراسات هامة ومتتوعة؛ ثلاث منها في مجال الاقتصاد، إلى جانب دراستين في مجال العلوم السياسية. وتعالج الدراسة الأولى موضوعاً حيوياً

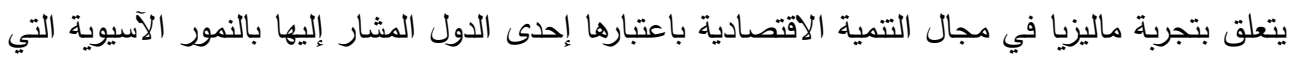

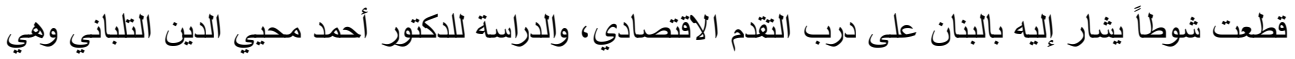

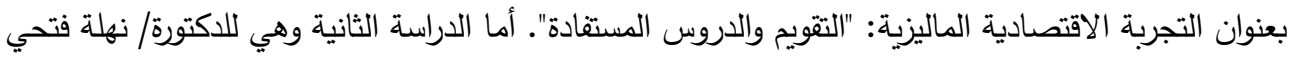

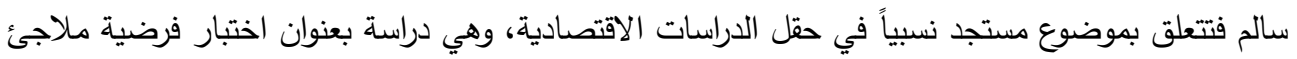
التلوث لدول الثرق الأوسط وشمال أفريقيا.

وينصب اهتمام الدراسة الثالثة على موضوع يتعلق بنظرية الأنساق الدولية وعلاقتها بالأنساق الإقليمية من خلال دراسة خاصة للنسق الإقليمي العربي خلال إحدى فترات التوتر التي شهرها محيطه الجغرافي إبان حقبة الحرب الباردة، والدراسة بعنوان تأثير النسق العالمي على الأنساق الإقليمية: دراسة حالة النسق الإقليمي العربي (1955-1967م) وهي لباحثة الدكتوراه/ إنجي أحمد.

أما الدراسة الرابعة؛ فتعرض بالتحليل لبعض التداعيات الدولية لظاهرة مستجدة في الدحيط الإقليمي

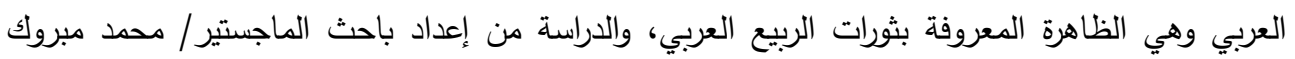

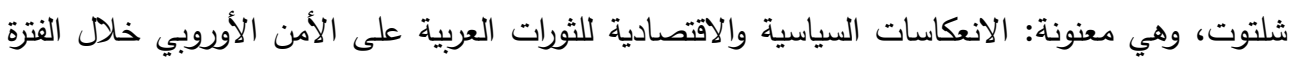
.2016: 2011

ثم تأتي الدراسة الخامسة والأخيرة في هذا العدد للدكتور / مصطفى السيد وهي دراسة باللغة الإنجليزية بعنوان: The impact of increasing public debt on real interest rate in Egypt (from 1982 to 2017) وهي تعالج قضية هامة بالنسبة للاقتصاد المصري تتعلق بأثر زيادة الدين العام على سعر الفائدة الحقيقي في مصر خلال الفترة 1982 : 2017. وهكذا تقطع المجلة العلمية لكلية الدراسات الاقتصادية والعلوم السياسية بجامعة الإسكندرية الشوط السابع نحو الريادة بين نظيراتها المتخصصة في مجالات الاقتصاد والعلوم السياسية على الصعيدين الوطني والإقليمي؛ وتقديم إضافة يعتد بها إلى البنية المعرفية العربية في ذينك التخصصين بهادين بالغي الأهمية. وكعادتنا

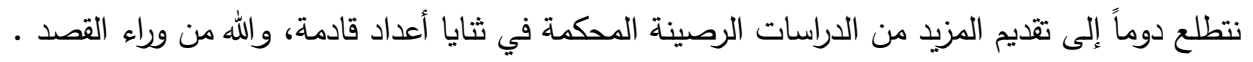

رئيس التحرير

أ.د. أحمد محمد وهبان 